\title{
FLOOR RESPONSE SPECTRA FOR BEYOND DESIGN BASIS SEISMIC DEMAND
}

\author{
Somnath Jha ${ }^{1}$, A.D. Roshan ${ }^{1}$, and L.R. Bishnoi ${ }^{2}$ \\ ${ }^{1}$ Scientific Officer, Siting and Structural Engineering Division, Atomic Energy Regulatory Board, \\ Anushaktinagar, Mumbai 400094 India (somnath@aerb.gov.in, adroshan@aerb.gov.in). \\ ${ }^{2}$ Director, Siting and Structural Engineering Division, Atomic Energy Regulatory Board, Anushaktinagar, \\ Mumbai 400094 India.
}

\begin{abstract}
Vulnerability assessment of Structures Systems and Components (SSCs) of nuclear facilities for earthquake ground motion exceeding the design basis ground motion has become an important exercise to ensure safety in case of highly improbable but possible extreme earthquake event beyond design basis. In order to assess seismic safety of SSCs located at different elevations in a building structure, floor response spectra (FRS) for such beyond design basis seismic demand, taking into account possible nonlinear behaviour of structure, is required. Currently used methods (e.g. IAEA Safety Series 28, [IAEA(2003)]) do not capture softening of structure at increased demand. A performance based approach would be ideal under such situations. FRS for higher seismic demand may be developed through nonlinear time history analysis of the structure. However, this approach is complicated and cumbersome and requires deep insight of solution algorithm and large resources for numerical solution. In this work a simplified methodology for FRS generation for higher level of seismic demand using linear time history analysis of an equivalent linear model is proposed. Nonlinear behavior of structure and associated damping are estimated from nonlinear static pushover analysis. Through this approach realistic estimation of degradation in stiffness of the structure and increase in damping at different levels of seismic demands can be made. Subsequently, linear time history analysis is performed on degraded structure, accounting for stiffness reduction and hysteretic damping to obtain the floor time histories which are then converted to FRS. Application of this method is shown through case studies.
\end{abstract}

\section{INTRODUCTION}

Seismic safety is one of the essential design requirements of a NPP structure. In order to assess seismic performance of Structures, Systems and Components (SSCs) located at different elevations, Floor Response Spectra (FRS) representing seismic demand at these elevations are required. These spectra are then used to qualify floor mounted SSCs. Generation of FRS requires dynamic analysis of the primary structure with specified base motion. Occurrence of recent seismic events (NCO earthquake of 2007 and GEJE event of 2011) that resulted in ground motions beyond design basis at many NPP sites has emphasized the need for assessment beyond design basis and evaluation of margins. With increase in demand, structure may exhibit nonlinear behavior resulting in softening (stiffness reduction) and change in natural frequencies. Nonlinear behavior of the structure also results in additional damping due to hysteresis. Conventional approaches (e.g. IAEA Safety Series 28) address this as an extension of existing seismic analysis methodologies albeit with use of increased damping and response reduction factors due to ductility.

The methodology proposed in this work for generation of FRS for seismic demand corresponding to beyond design basis seismic events is based on state of the art performance based structural assessment procedures viz. nonlinear Static Pushover Analysis (NLSPA). Though non-linear dynamic time history 
analysis is a more rational method, its complexity of response tracking, uncertainties associated with material constitutive laws and impact on solution accuracy are the deterrents for design office use. Simplicity of pushover analysis makes it more appealing for design office use. Pushover curve of the structure depicts degradation in the stiffness of the structure at different levels of seismic demand. Hysteretic damping due to nonlinear behavior of the structure could also be evaluated from pushover curve using empirical approaches given in various international guidelines viz. ATC-40 (1996), NUREG/CR-3805 [Kennedy R.P et. al, (1984)], etc. Linear time history analysis performed on a degraded structure accounting for stiffness degradation and enhanced hysteretic damping yields the floor response spectra for Seismic Demand corresponding to Beyond Design Basis Earthquake (BDBE).

\section{SEISMIC PERFORMANCE ASSESSMENT USING PUSHOVER ANALYSIS}

The two key points of a performance based analysis procedure are demand and capacity. Demand is the representation of the earthquake ground motion. Capacity is the representation of structure's ability to resist seismic demand. Pushover analysis is a static, non-linear procedure in which magnitude of lateral loading is increased in steps in accordance with a certain predefined pattern and the response reflects capacity of structure against lateral force.

Once capacity curve of the structure is established, performance assessment of the structure can be done using capacity spectrum method [ATC-40, (1996)]. In this method, capacity of structure is compared with seismic demand in Acceleration Displacement Response Spectrum (ADRS) format to assess the seismic performance of structure. In order to determine performance of a structure for a given seismic motion, displacement along the capacity curve is determined that is consistent with seismic demand. The procedure seeks to find out a point on the capacity spectrum that also lies on the appropriate demand spectrum, scaled down for nonlinear effects. This point is called performance point.

Spectral reduction factors are applied on the demand spectrum to account for hysteretic damping. An approximate effective (hysteretic) damping is calculated based on the capacity curve, the estimated displacement demand and resulting hysteresis loop. Probable imperfections in real building hysteresis loops, including degradation and duration effects, are accounted for by reducing theoretically calculated equivalent viscous damping values.

\section{ESTIMATION OF HYSTERETIC DAMPING}

Hysteretic damping is related to the area inside the loops that are formed when the earthquake force (base shear) is plotted against the structure displacement. Hysteretic damping can be represented by equivalent viscous damping using equations available in the literature.

In the present study, equivalent viscous damping of frame structures (i.e. with beam and columns), is estimated from ATC-40 (1996). For shear wall structures, equation given in ATC-40 (1996) may overestimate the hysteretic damping [Gulkan et. al. (2005)]. High damping values are not expected for shear wall structures (squat shear walls in particular) due to considerably lower ultimate displacement demand than frame structures and existence of pinching in the hysteresis loop for shear walls resulting in further reduction in damping. If one were to use the original equation given in ATC-40, owing to higher estimates of damping values for shear walls, the displacement demand for a given ground motion would be under-predicted. For experiments conducted on shake table under significant damage conditions, the maximum value of damping in $\mathrm{RC}$ wall-frame system ranges from 6.9\% - 7.5\% [PEER/ATC-72 (2005)], whereas damping predicted by equation given in ATC-40 results in values as high as $20 \%$ in some cases. 
Recognizing this problem, some researchers have proposed equations for estimation of equivalent viscous damping of shear wall structures. Accordingly, equation given by Kennedy R.P et. al, (1984) for damping of shear walls accounting for structure specific characteristics was selected for current study. More details on comparison of damping from different formulations and validation of equation used in the present study are available in a companion paper [Jha et. al, (2015)].

\section{EVALUATION OF STIFFNESS REDUCTION}

Reduction of stiffness of the structure is evaluated by comparing the initial stiffness with the secant stiffness for a particular displacement demand. Displacement demand is lateral displacement of the structure corresponding to the performance point for a specified ground motion.

Stiffness reduction factor $=$ Secant stiffness $/$ Initial stiffness

This reduction factor is applied uniformly on stiffness of all the components (beams, columns) that contributed to nonlinear behavior under the specified seismic demand such that the overall structural stiffness is representative of the softened structure at performance point. In this way the global nonlinear behavior of structure can be accounted. This methodology has limitations as the stiffness reduction is not done locally. However, this approximation would still be reasonable in view of the fact that any local reduction of stiffness would result in redistribution of demand among individual members and thus degrading the global behavior.

\section{GENERATION OF FRS}

Once pushover curve of the structure is generated and performance assessment for evaluation of displacement demand is done, equivalent viscous damping and stiffness reduction factor can be calculated following approaches outlined in previous sections. Linear time history analysis of the degraded structure (reduced stiffness) is performed for the estimated viscous damping. FRS is generated from the results of linear time history analysis.

\section{CASE STUDIES FOR GENERATION OF FRS FOR BDBE}

The methodology discussed in previous sections for generation of FRS for BDBE is applied to two sample structures. First structure is a conventional RC shear wall-frame building located in a high seismic zone, designed following Indian Standard Code of Practice [IS: 1893 (2002)]. The second is a typical NPP structure in a moderate seismic zone.

Pushover analysis is performed on the mathematical model of the structures to evaluate equivalent viscous damping and corresponding stiffness reduction factors at specified seismic demand. After modifying FE model for stiffness degradation and associated damping obtained from pushover analysis, linear time history analysis is performed on modified FE model of the structure to generate FRS that can be used for further evaluation of equipment and components for corresponding level of seismic demand.

\section{FRS FOR CONVENTIONAL STRUCTURE}

A three storied RC shear wall-frame structure with plan dimensions of $24 \mathrm{~m} \times 24 \mathrm{~m}$, grid size of $6 \mathrm{~m} \times 6 \mathrm{~m}$ and floor height of $4 \mathrm{~m}$ is considered for analysis. Analysis and design of structure is carried out following requirement of IS 1893 (part-1) (2002) and detailing (of shear wall) is carried out following IS-456 (2000) and IS- 13920 (1993). Load factor is considered as unity. More details on design of this structure are available in the companion paper [Jha et. al, (2015)]. Seismic input is the design spectral shape given in 
IS-1893 (Part-1) (2002) anchored to a PGA of 0.24g corresponding to seismic zone IV of IS-1893. General layout of structure and finite element model are shown in Figure-1 and Figure-2 respectively. Average element size is about $0.7 \mathrm{~m}$.

Lateral load analysis of the structure indicates that more than $95 \%$ of the base shear due to earthquake load is shared by shear walls oriented in the direction of the motion. Contribution of columns to resist base shear is less than $3 \%$ and shear walls in other direction contributes to around $2 \%$. As majority of the lateral load due to earthquake is taken by shear walls only, pushover analysis is performed on the shear walls instead of whole building to evaluate the lateral load deformation of the structure.

\section{Pushover analysis of shear wall}

FE model of the shear wall is developed in ABAQUS ${ }^{\circledast}$ using four noded shell element with smeared layer of reinforcement (type S4R). Nonlinear behavior of concrete is modeled using concrete damage plasticity material model of ABAQUS ${ }^{\oplus}$. This material model has been calibrated and validated for prediction of inelastic behavior of shear wall under lateral loads by comparison of data from experiments on shear walls with varying aspect ratio [Jha et. al. (2013)]. Reinforcement detailing of wall is shown in Figure-3.

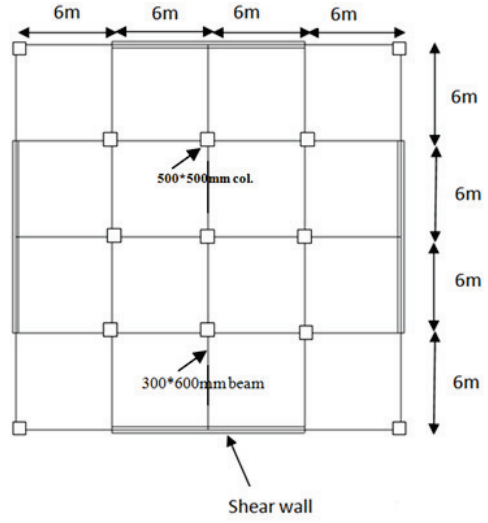

Figure-1 Layout of conventional building structure

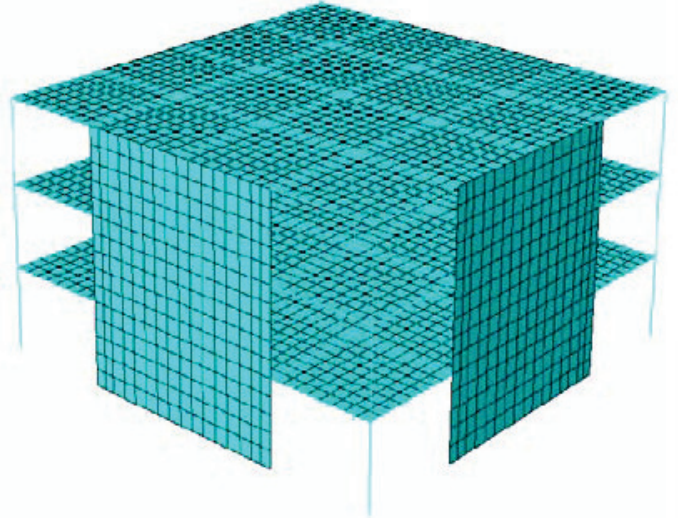

Figure-2 FE model of the structure

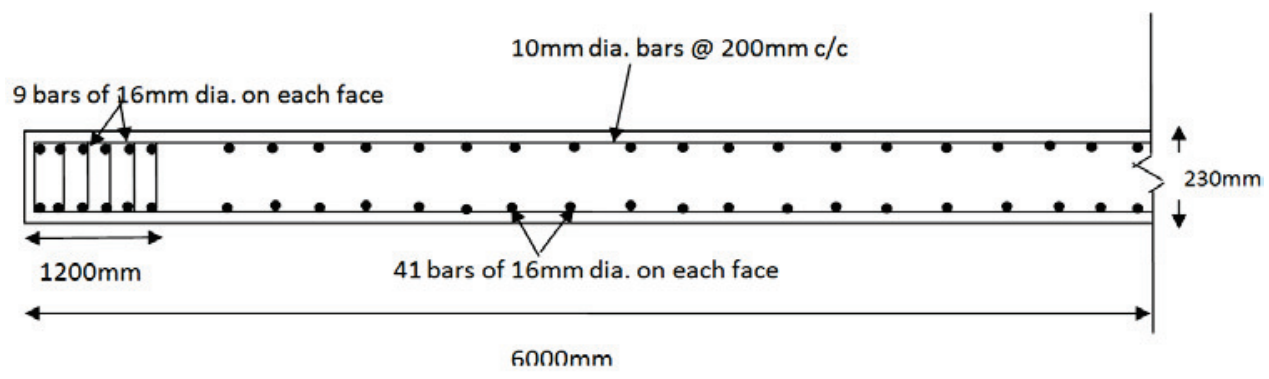

Figure-3 Cross-section detail of shear wall

Pushover analysis of shear wall under monotonically increasing load is carried out with lateral load distribution corresponding to first mode and capacity curve of the wall is evaluated. 


\section{Performance assessment of shear wall}

Performance assessment is done for response spectra corresponding to Safe Shutdown Earthquake (SSE) for an Indian NPP site in a moderate seismic zone and postulated Beyond Design Basis Earthquake (BDBE) for the same site. Pushover curve of the wall is converted into capacity spectrum and is superimposed with demand spectra (SSE and BDBE) in acceleration displacement response spectrum (ADRS) format as shown in Figure-4.

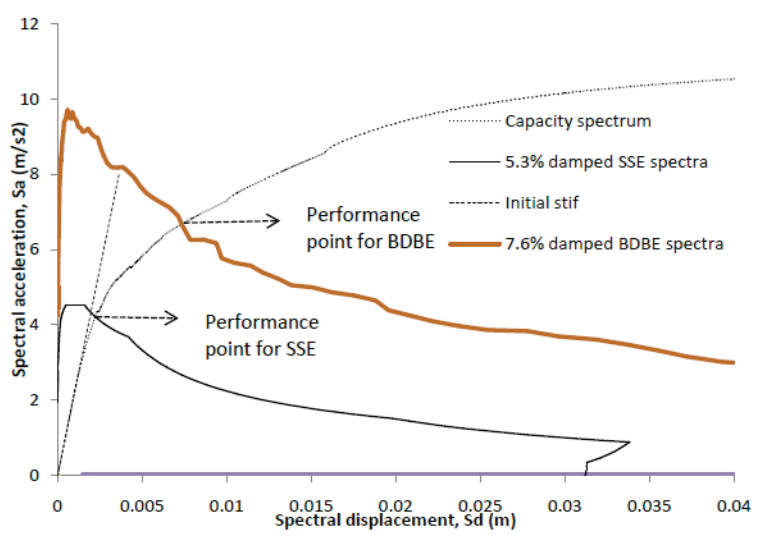

Figure-4 Performance assessment of shear wall

\section{Calculation of stiffness reduction and equivalent damping}

Based on performance point corresponding to SSE and BDBE levels of seismic ground motion, stiffness reduction factors and equivalent damping due to nonlinear deformation are evaluated as per the procedure mentioned previously. For estimation of equivalent viscous damping, formulation for shear wall has been applied [Kennedy R.P et. al, (1984)] with elastic damping of 5\%. Since design spectrum of IS-1893 (2002) for the structure correspond to a high seismic zone, it is comparable to SSE spectrum for the NPP site which is a moderate seismic zone, degradation in stiffness is insignificant whereas it is significant for BDBE level of ground motion. Stiffness reduction factors and equivalent damping values are given in Table-1 below.

Table-1 Stiffness reduction factor and hysteretic damping for conventional building structure

\begin{tabular}{|l|l|l|}
\hline Earthquake level & SSE & BDBE \\
\hline Stiffness reduction factor & 0.9 & 0.4 \\
\hline Equivalent damping & $5.33 \%$ & $7.60 \%$ \\
\hline
\end{tabular}

\section{Generation of FRS}

Linear time history analysis on FE model of full structure (including beam, column, walls and slab) is performed to generate FRS. Stiffness of the shear wall is modified to account for stiffness degradation. Cracked section behavior is considered for beams and columns. ASCE 43-05 suggests initial stiffness value of $0.5 \mathrm{EI}$ for beams and $0.7 \mathrm{EI}$ and $0.5 \mathrm{EI}$ for column under compression and tension respectively. As columns may undergo both tension and compression under cyclic loading scenario during earthquake, 0.5EI was uniformly adopted for all the structural components (beams and columns). In order to model degradation in shear wall under SSE \& BDBE, modulus of elasticity of concrete is reduced in line with 
the stiffness reduction factor. Modal time history analysis has been performed with the modified FE model of the full structure including enhanced equivalent damping to generate floor time history used for calculating FRS.

Figure-5 shows the FRS of the structure at top floor for SSE and BDBE level of seismic ground motion accounting for stiffness reduction and hysteretic damping as discussed earlier. Since there is no perceptible non-linear response up to SSE motion, there is no stiffness degradation and no damping enhancement. This is why the peak of FRS due to SSE is higher than that due to BDBE wherein such effects have caused significant reduction of peak values as seen in Figure-5 In order to see the effect of degradation and hysteretic damping, results of analysis using BDBE motion on the structure without degradation is compared with the result of degraded structure under BDBE in Figure-6. It is seen that the effect of stiffness degradation and enhanced damping is perceptible for BDBE but not so in case of SSE. Owing to predominantly high frequency content of spectra considered, the reduction in structural frequency under BDBE due to degradation is seen to result in relatively lower spectral acceleration demand compared to that for a non-degraded structure.

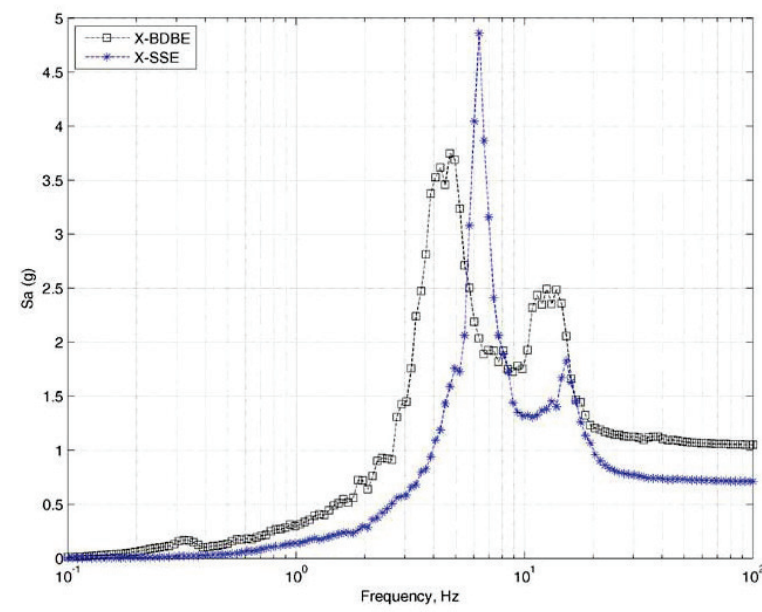

Figure-5 FRS of the structure at top floor for SSE and BDBE

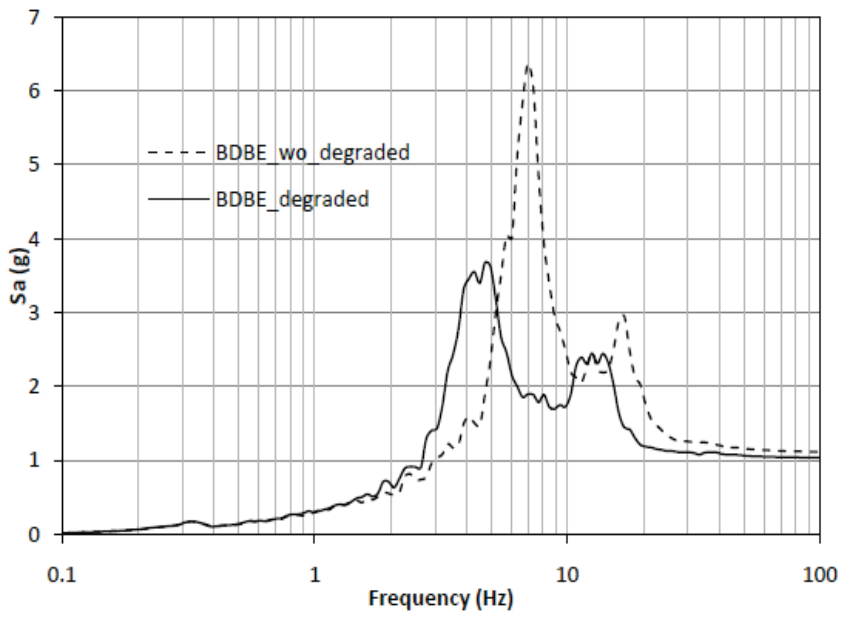

Figure-6 Comparison of FRS showing effect of degradation in structure

\section{FRS UNDER BDBE FOR A TYPICAL NPP STRUCTURE}

The exercise of generation of FRS under BDBE is extended for a typical RC-framed shear wall type NPP structure. Considered building is a multi-storied RCC Framed structure with approximate plan size of 55 $\mathrm{m} \times 42 \mathrm{~m}$ and height of $24 \mathrm{~m}$ including $8 \mathrm{~m}$ basement.

\section{Pushover analysis of the structure}

3-dimensional mathematical model of the structure has been developed using ABAQUS ${ }^{\circledR}$ for pushover analysis. Structural elements such as beams, columns, slabs, and RC walls are included in modeling. The structure is assumed to be fixed on top of the raft. 

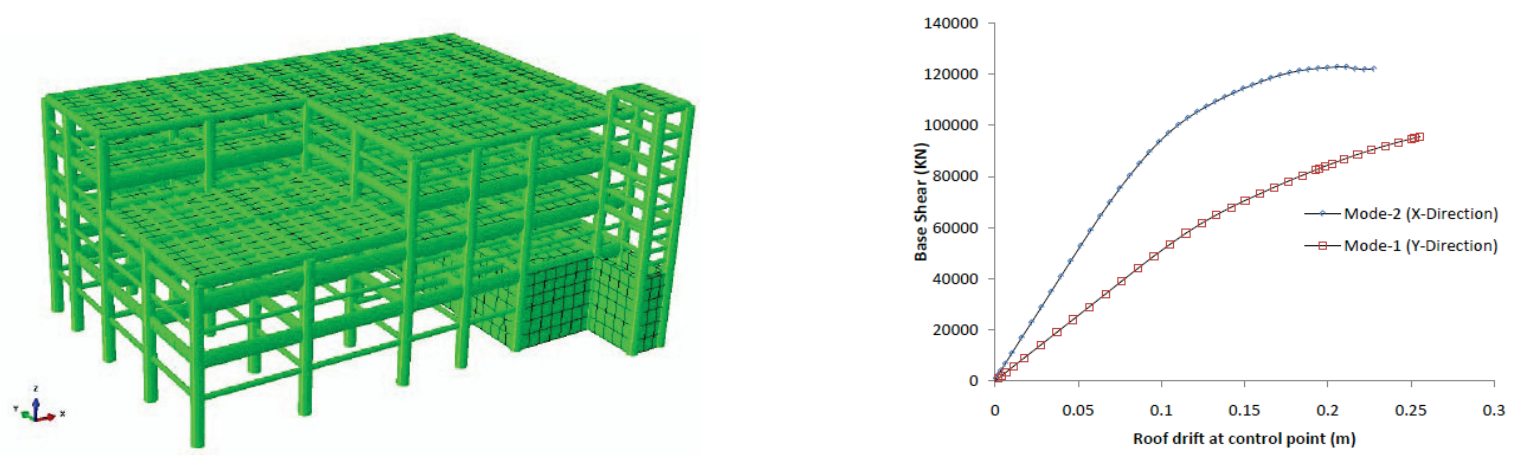

Figure-7 FE model of the structure

Figure-8 Pushover curves for fundamental modes of vibration

Beams and columns are modeled using 3D beam elements (type B31) with moment-curvature (M-phi) curves for nonlinear behavior. M-phi curves are derived considering nonlinear concrete and steel properties. Shear wall is modeled using 4 node shell elements (type S4R) with concrete damage plasticity model. RC floor slab is relatively rigid (in-plane) and does not undergo deformation to maintain compatibility, these are modeled with linear elastic properties. Initial flexural stiffness for beams and columns is taken as $0.5 \mathrm{EI}$ to represent cracked section behavior. FE model of the structure for pushover analysis is shown in Figure-7. As structure has unsymmetrical mass/ stiffness distribution, pushover analysis is carried out for first two fundamental modes of vibration in orthogonal horizontal directions. Pushover curves of the structure are shown in Figure-8.

\section{Seismic performance assessment}

In addition to SSE and BDBE level of ground motion, seismic performance assessment of the structure is also carried out for ground motion corresponding to collapse limit state of ASCE-43-05 (LS-A). Time history and response spectra for LS-A is obtained by augmenting the SSE time history/ response spectra by a multiplication factor. This factor is calculated as ratio of PGA corresponding to LS-A performance level to PGA of SSE. PGA of ground motion for SSE, BDBE and LS-A are $0.191 \mathrm{~g}, 0.490 \mathrm{~g}$, and $0.718 \mathrm{~g}$ respectively. Figure- 9 shows comparison of capacity and demand spectrum for performance assessment for different ground motions.

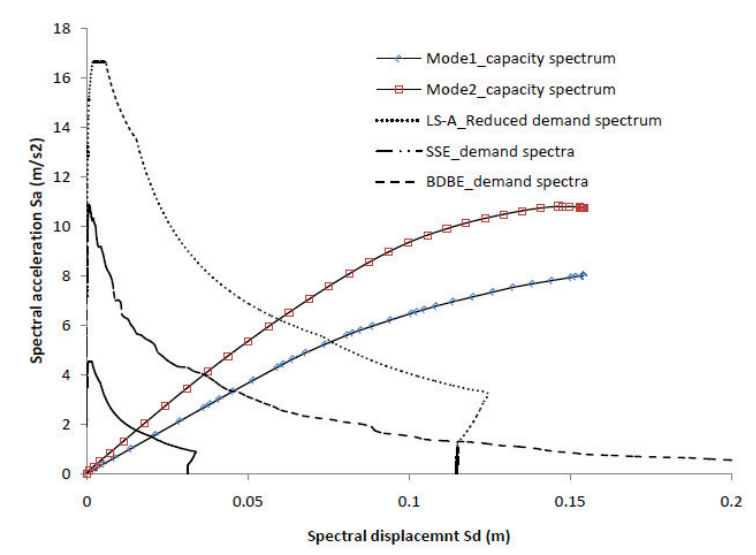

Figure-9 Comparison of capacity and demand spectra 


\section{Calculation for stiffness degradation and viscous damping}

Due to higher capacity of the present structure, stiffness degradation does not seem to occur under SSE and BDBE ground motion. However, for LS-A ground motion some amount of reduction in stiffness is observed. Behavior of shear wall in this structure is almost elastic even at ultimate base shear. Hence no degradation in shear wall stiffness is accounted in further time history analyses. As there is no reduction in stiffness of shear wall for SSE and BDBE ground motion level, no enhancement of hysteretic damping is expected. For LS-A level of ground motion, hysteresis in non-linear range further contributes to overall damping.Table-2 shows the stiffness degradation factors and damping for different directions for SSE, BDBE and LS-A level of seismic motion.

Table-2 Stiffness degradation factors and hysteretic damping

\begin{tabular}{|l|l|l|l|l|l|l|}
\hline Direction $\rightarrow$ & X-Direction (mode2) & \multicolumn{2}{l|}{ Y-Direction (mode1) } \\
\hline Earthquake level $\rightarrow$ & SSE & BDBE & LSA & SSE & BDBE & LSA \\
\hline Stiffness reduction factor & 1 & 1 & 0.94 & 1 & 1 & 0.98 \\
\hline Equivalent damping & $7 \%$ & $7 \%$ & $8.30 \%$ & $7 \%$ & $7 \%$ & $7.56 \%$ \\
\hline
\end{tabular}

\section{Generation of FRS}

After evaluating the stiffness reduction factor and the equivalent damping from performance assessment of structure, FE model of the structure is modified to account for stiffness degradation. However, it is noted that, no degradation is observed for SSE and BDBE level of earthquake and hence stiffness and damping is not modified for these conditions except for LS-A. Flexural stiffness of the structural elements (beams and columns) is reduced for degrading the stiffness of the structure for LS-A level of seismic motion.

Four cases are considered for modal time history analysis of the structure. These include time history analysis on model with:

(i) Full stiffness for SSE with 7\% damping;

(ii) Flexural stiffness of beam and column equal to $0.5 \mathrm{EI}$ for SSE with 7\% damping;

(iii) Flexural stiffness of beam and column equal to $0.5 \mathrm{EI}$ for BDBE with $7 \%$ damping;

(iv) Modified stiffness for LS-A with damping obtained from performance assessment.

FRS for the top floor in two horizontal direction X (N-S) \& Y (E-W) for the four cases considered in the study are shown in Figure-10. 

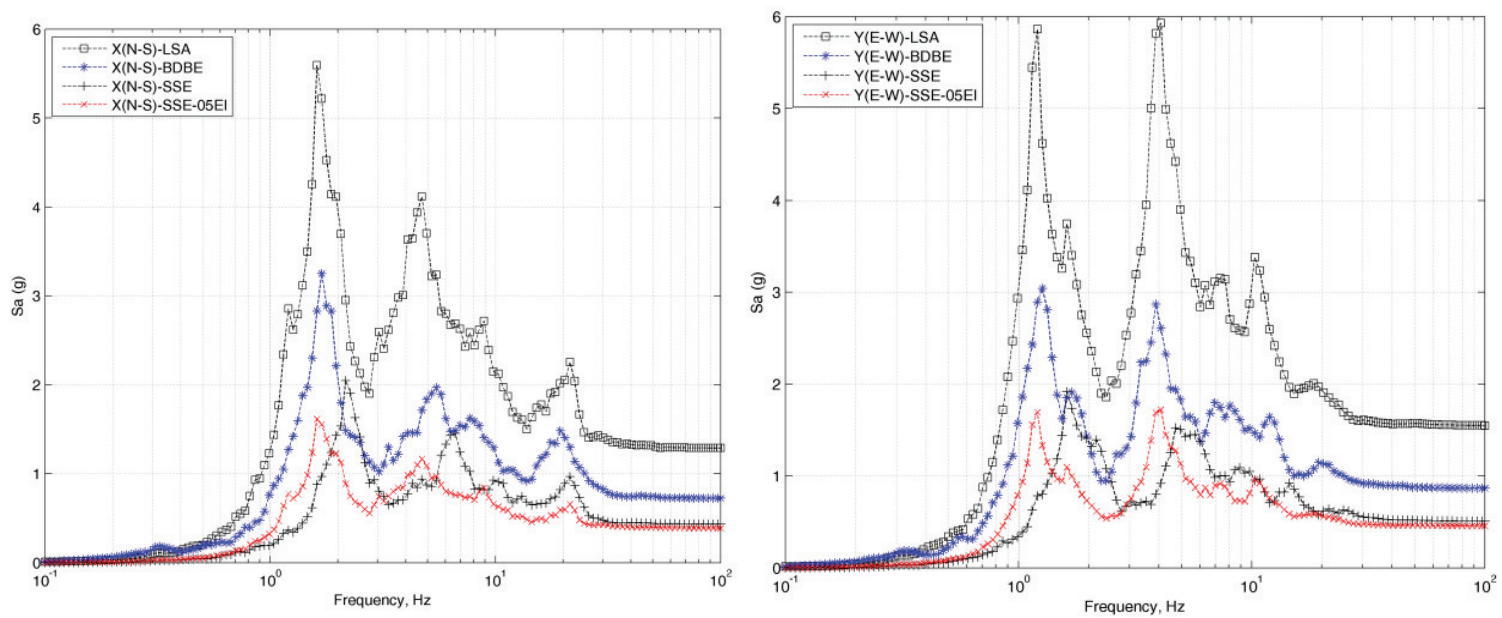

Figure-10 FRS for top floor in X \& Y direction

\section{SUMMARY AND CONCLUSIONS}

For conventional building structure it is seen that, due to degradation of stiffness and higher value of equivalent damping for BDBE level of ground motion, attenuation of FRS is very high compared to SSE. Frequency shift on account of stiffness degradation is also captured under BDBE condition.

For NPP structure, performance assessment shows that there is no degradation of the structure even for BDBE level of ground motion. This is due to higher seismic capacity of the structure. However, as cracked flexural stiffness $(0.5 \mathrm{EI})$ is used in evaluation, fundamental frequency of the structure has changed from $1.55 \mathrm{~Hz}$ to around $1.23 \mathrm{~Hz}$. This reduction in stiffness / frequency results in lesser demand (as per the shape of the input spectra) and in turn lesser amplification of the peak of FRS at top floor for the present structure. At top floor of the structure dynamic amplification of zero period acceleration (ZPA) in lateral direction for BDBE is about 1.81 and for SSE it is about 2.32. Dynamic amplification of peak spectral acceleration in lateral direction at top floor for BDBE is about 2.93 and for SSE is about 2.97 .

The following conclusions are drawn from the current study.

1. If there is a perceptible degradation of the structure exposed to ground motion higher than its design basis (i.e. BDBE motion), the resultant floor response spectra would shift to lower frequencies and peak value of floor acceleration also reduces. This is due to softening of the rigidity on account of material degradation and consequent enhancement in damping (energy absorption) of the structure.

2. If there is no significant degradation of the structure under BDBE (i.e. the structure has large margin over its design basis earthquake), there is no change in shape of the floor response spectra (FRS) compared to the FRS based on linear analysis. Thus the amplification scales linearly.

3. It is thus implied from (1) and (2) that the FRS would monotonically and linearly increase over their design basis values when subjected to higher seismic demand until there is perceptible damage to the structure. Subsequent increase in demand would result in reduction of spectral acceleration due to reduced amplification. The peak values of FRS would reduce but there would be over all broadening of the spectrum. This in turn implies that at several frequencies the acceleration based on non-linear FRS may be higher than that based on linear analysis. 
4. Further refinement of the proposed method can be made accounting for multi-mode; multi directional push over methods. It may be also noted that the proposed method does not capture progressive non-linearization of dynamic response and resulting effect on FRS.

\section{REFERENCES}

Abaqus-6.10, (2010), "Abaqus 6.10 User Documentation - User Mannual”, Dassult Systems Simulia Crop., Providence, RI, USA.

ASCE-43/05, (2005), "Seismic Design Criteria for Structures, Systems, and Components in Nuclear Facilities" American Society of Civil Engineers.

ATC-40, (1996), "Seismic Evaluation and Retrofit of Concrete Buildings", Report No. SSC 96-01, Applied Technology Council, California Seismic Safety Commission, California November 1996.

Gülkan P, I. Kazaz. I and A. Yakut A, (2005), "Caveats For Nonlinear Response Assessment of ShortPeriod Structures", Earthquake Engineering Research Center, Disaster Management Research Center, Department of Civil Engineering, Middle East Technical University.

IAEA, (2003), Seismic Evaluation of Existing Nuclear Power Plants, International Atomic Energy Agency, IAEA Safety Reports Series.No.28, Vienna.

IS-1893 (part1), (2002), Indian Standard, "Criteria for earthquake resistant design of structures, part 1 general provisions and buildings (Fifth Revision)", Bureau of Indian Standards, New Delhi.

IS 456, (2000), Indian Standard, "Plain and reinforced concrete - Code of Practice (Fourth Revision)", Bureau of Indian Standards, New Delhi.

IS-13920, (1993), Indian Standard "Ductile Detailing of Reinforced Concrete Structures Subjected To Seismic Forces", Bureau of Indian Standards, New Delhi.

Jha S, Bharghava K, Bishnoi L. R., Roshan A. D and Basu S. (2013) "Numerical Simulation of Shear Wall Nonlinear Behavior Subjected to Lateral Loads" ; 22nd International Conference on Structural Mechanics in Reactor technology (SMiRT-22), San Francisco, USA, Paper \# 268, Division VII.

Jha S, Bharghava K, Bishnoi L. R., Roshan A. D and Basu S. (2015) "Seismic Margin Assessment of Shear Walls with Different Aspect Ratio" ; 23 $3^{\text {rd }}$ International Conference on Structural Mechanics in Reactor technology (SMiRT-23), Manchester, United Kingdom, Paper \# 451, Division IX.

Kennedy, R. P., Short, S. A., Merz, K. L., Tokarz, F. J., Idriss, I. M., Power, M. S., and Sadigh, K., (1984), "Engineering Characterization of Ground Motion, Task 1: Characteristics of Free- Field Motion on Structural Response," NUREG/CR-3805, Structural Mechanics Associates, Inc. and Woodward-Clyde Consultants.

PEER/ATC-72-1 (2010), "Modeling and Acceptance Criteria for Seismic Design and Analysis of Tall Buildings", Applied Technology Council, California. 